\title{
Unión marital de hecho: análisis jurisprudencial desde el derecho a la igualdad para los compañeros permanentes
}

\author{
Martha I. Pérez-Estupiñán ${ }^{\star}$ Walter Guevara-Vargas ${ }^{\star *}$, José A. Ariza-García ${ }^{\star \star *}$
}

* Magíster (c) en Derechos Humanos de la Universidad Industrial de Santander, Colombia. Abogada de la Universidad Cooperativa de Colombia, sede Bucaramanga.

Correo electrónico: maperez@uis.edu.co

** Abogado de la Universidad Cooperativa de Colombia, sede Bucaramanga. Asesor jurídico independiente, Colombia.

Correo electrónico: distriwal@hotmail.com

*** Abogado de la Universidad Cooperativa de Colombia, sede Bucaramanga. Asesor jurídico independiente, Colombia.

Correo electrónico: jaagcalifornia2008@hotmail.com

Recibido: 14 de diciembre del 2012 Aprobado: 31 de marzo del 2013

Cómo citar este artículo: Martha I. Pérez-Estupiñán, Walter GuevaraVargas \& José A. Ariza-García. Unión marital de hecho: análisis jurisprudencial desde el derecho a la igualdad para los compañeros permanentes. DIxı. Junio 2013. At. 89.

\begin{abstract}
Resumen
La unión marital de hecho, como institución humana conformadora de familia, es una realidad y un tema fundamental para esta investigación, cuyo punto de partida es una introspección sobre la familia formada por vínculos naturales frente a la conformada por vínculo de matrimonio. Las grandes transformaciones culturales y el cambio de mentalidad alrededor de la familia, exigen mirar a cónyuges y compañeros permanentes en la misma esfera de valores derechos y deberes, por lo que el derecho a la igualdad es la piedra angular de los pronunciamientos de las Altas Cortes de cara a la situación de la familia en Colombia.
\end{abstract}

Palabras clave: análisis jurisprudencial, familia y derecho a la igualdad, unión marital de hecho, y derecho a la igualdad.

De facto Marital Union: a Jurisprudential Analysis from the Perspective of the Right to Equality for Partners

\begin{abstract}
The de facto marital union as a family-shaping human institution is a reality and is central to this research, which begins by looking at the family formed by natural links as compared to the family created through marriage. The great cultural transformations and changing mentalities regarding the family make it necessary to regard spouses and permanent partners in the same realm of rights and duties. That is why the right to equality is the cornerstone of rulings by the high courts with reference to the situation of the family in Colombia.
\end{abstract}

Keywords: jurisprudential analysis, the family and the right to equality, de facto marital union, right to equality.

\section{UNIÃo MARITAL DE FATO: ANÁLISE JURISPRUDENCIAL A PARTIR DO DIREITO À LEGALIDADE PARA OS COMPANHEIROS PERMANENTES}

\section{Resumo}

A união marital de fato, como instituição humana conformadora de família, é uma realidade e um tema fundamental para esta pesquisa, cujo ponto de partida é uma introspecção sobre a família formada por vínculos naturais em relação à conformada por vínculo de matrimônio. As grandes transformações culturais e a mudança de mentalidade sobre a família exigem ver os cônjuges e companheiros permanentes na mesma esfera de valores, direitos e deveres, razão pela qual o direito à igualdade é a pedra angular dos pronunciamentos das Altas Cortes de cara à situação da família na Colômbia.

Palavras-chave: análise jurisprudencial, família e direito à igualdade, união marital de fato e direito à igualdade. 


\section{INTRODUCCIÓN ${ }^{1}$}

La familia es el núcleo fundamental de la sociedad. Se constituye por vínculos naturales o jurídicos, por la decisión libre de un hombre y una mujer de contraer matrimonio o por la voluntad responsable de conformarla [...]. Constitución Política de Colombia, art. 42.

Con este precepto, plasmado en el artículo 42 de la Constitución Política de Colombia, se parte a una investigación sobre la realidad de las parejas de hecho en nuestro país, su situación jurídica después de la Constitución de 1991, y por supuesto se pondrá sobre el tapete un tema de álgida discusión, como es el derecho a la igualdad para las uniones maritales de hecho tanto para parejas heterosexuales como homosexuales, visto desde la óptica de las tres Altas Cortes. El análisis jurisprudencial que se plantea en esta investigación toma como base imprescindible de estudio, la posición enfática, constante y sólida de la Corte Constitucional respecto al derecho a la igualdad, cuya enmienda primordial reiterada en su jurisprudencia aplicable a todos los hechos y actos jurídicos describe: "iguales ciudadanos deben tener iguales derechos y obligaciones fundamentales". ${ }^{2}$ La eliminación de toda forma de discriminación es uno de los objetivos esenciales de la Corte para el cumplimiento cabal de los preceptos constitucionales; desde esta óptica, la familia como núcleo esencial de la sociedad, es por excelencia la razón y el fundamento para la garantía y la protección de derechos de quienes la conforman. Fue precisamente en uno de los grandes debates de la Asamblea Nacional Constituyente que se elevó a rango constitucional el art. 42, relativo a la familia, en cuya exposición de motivos se expresó su sentido y se le otorgó el estatus ante la sociedad y el Estado. ${ }^{3}$ En este sentido, es im-

$1 \mathrm{El}$ presente artículo es producto de la investigación terminada en la Facultad de Derecho de la Universidad Cooperativa de Colombia, sede Bucaramanga, titulado "Unión marital de hecho: desarrollo jurisprudencial en Colombia periodo 2005-2012", bajo la dirección de Sandra Elizabeth Durán Prada.

2 Ver Daniel Bonilla. Corte Constitucional, igualdad y orientación sexual. http://www.viva.org.co/cajavirtual/svc0051/articulo02.pdf. Enero 2012. Expone la teoría de la Corte, así: "ni la administración, ni el Congreso, ni los jueces, pueden utilizar el derecho, el presupuesto nacional o el poder coercitivo del que disponen para privilegiar a algunos de sus ciudadanos, aún si éstos constituyen la mayoría dentro de la comunidad política”.

3 Las personas unidas entre sí por vínculos naturales, como los diferentes grados de consanguinidad, o unidas por vínculos jurídicos, que se presentan entre esposos, afines o entre padres adoptivos, o por la voluntad prescindible buscar cuál es la razón para que la familia conformada por vínculos naturales haya sido desconocida desde el punto de vista legal, tal como se refleja en la normatividad vigente.

Después de la Constitución de 1991, jueces y magistrados se han dado a la tarea de buscar métodos de interpretación e integración para suplir las contradicciones y vacíos de la norma, que afecta a los compañeros permanentes. La problemática de las omisiones legislativas no es un asunto que atañe sólo al sistema judicial colombiano, pues en el derecho comparado se puede comprobar que es un dilema que traspasa fronteras, que ocupa la atención de sistemas judiciales, los cuales, aún con sus limitaciones, buscan un equilibrio para la operatividad y efectividad del aparato judicial, afectado por las lagunas de la norma. El vacío normativo, ampliamente debatido, será el juicio de reproche al que se verá siempre expuesto el legislador. Respecto a este tema, Habermas (1998), ha dicho que "como la práctica de las decisiones judiciales está ligada al derecho y a la ley, la racionalidad de la administración de justicia depende de la legitimidad del derecho vigente". Esto no es otra cosa que el papel de los jueces vista en sus decisiones. En este sentido, Habermas igualmente señala:

Un orden jurídico no sólo tiene que garantizar que cada persona sea reconocida en sus derechos por todas las demás personas, sino que el reconocimiento recíproco de los derechos de cada uno por todos los demás tiene que descansar en leyes que sean congruentes, legítimas en la medida en que garanticen iguales libertades a todos, no de manera contradictoria sino igualitaria $(\mathrm{Ha}-$ bermas, 1998). ${ }^{4}$

Las omisiones legislativas son el fundamento de la gran mayoría de las demandas de constitucionalidad, y para el caso que nos ocupa respecto de los compañeros permanentes, tanto de parejas heterosexuales como homosexuales, que han sido excluidas de la norma, apareciendo sólo el cónyuge como titular de derechos y garantías. Esto reviste una gran connotación, por cuanto se trata de la seguridad jurídica que tanto se defiende en los estrados judiciales, que es el aside-

responsable de constituirla, en los casos en que un hombre y una mujer se unen con la decisión de vivir juntos, tienen pleno derecho a conformar y desarrollar esta base de la sociedad, aunque no tengan entre sí vínculos de sangre ni contractuales formales, si llenan los requisitos de ley, su conciencia, sus costumbres o tradiciones, su religión o sus creencias.

4 Ver Jürgen Habermas. Facticidad y validez. Trotta. (1998). 
ro de esperanza del ciudadano y "el derecho a la igualdad", principio que debe ser reafirmado desde la óptica del sentido de la justicia, como lo expresa John Rawls (2006):

La justicia es la primera virtud de las instituciones sociales, como la verdad lo es de los sistemas de pensamiento. Una teoría, por muy atractiva y esclarecedora que sea, tiene que ser rechazada o revisada si no es verdadera; de igual modo, no importa que las leyes e instituciones estén ordenadas y sean eficientes: si son injustas han de ser reformadas o abolidas. ${ }^{5}$

\section{II. ¿CUÁl ha SIDO EL AVANCE JURISPRUDENCIAL PARA LAS UNIONES MARITALES DE HECHO RESPECTO A IGUALDAD DE DERECHOS DESDE LA PERSPECTIVA DE CONFORMACIÓN}

\section{DE FAMILIA?}

Sin pecar de alarmistas, podría decirse que las instituciones a todo nivel en Colombia han perdido credibilidad, y las instituciones como la familia y el matrimonio han sufrido transformaciones sociales, políticas y sobre todo jurídicas, que merecen una verdadera radiografía y estudios profundos, ya que son la sociedad misma en toda su expresión. Maria Luisa Cassanmagnago Cerretti (1998) nos ilustra al respecto en sus estudios sobre la construcción social de los problemas familiares, cuando expresa:

Es sorprendente que la desintegración generalizada del concepto de la familia como núcleo de la sociedad, la cada vez mayor inestabilidad de las relaciones familiares que se reflejan en la propagación de la unión libre y del divorcio, la nueva posición de la mujer en la sociedad y su afán de integrarse al mercado laboral, la cada vez menor tasa de nacimientos, que en la actualidad se aproxima, o es menor a la tasa estipulada para la autorrenovación de la población, sean tendencias afines a todos los países aun cuando puedan variar en intensidad.

En las últimas décadas, las uniones maritales de hecho, como conformadoras de familia, han cobrado una real y mayor importancia, debido precisamente

5 Ver John Rawls. La Teoría de la Justicia. Fondo de Cultura Económica. (2006). a la poca confianza que ciertos grupos sociales le dan al matrimonio. Esto no quiere decir que el matrimonio no siga siendo valorado, y que se mantenga como una institución social importante, pese a que algunos lo consideren anticuado e innecesario para formar una familia. Siendo hoy la unión marital de hecho una institución del mismo raigambre social que el matrimonio, han existido -incluso después de la Constitución de 1991- diferenciaciones desde las Altas Cortes, como es el caso de uno de los primeros fallos de constitucionalidad en el que se hace palpable esta discriminación, expresada en la Sentencia C-239 de $1994^{6}$-en la que se analizó si se estaba dando un trato distinto y derechos distintos a la pareja formada por el matrimonio y a la formada por vínculos naturales- cuyo texto es el siguiente:

Es erróneo sostener que la Constitución consagre la absoluta igualdad entre el matrimonio y la unión libre, o unión marital de hecho. Sostener que entre los compañeros permanentes existe una relación idéntica a la que une a los esposos, es afirmación que no resiste el menor análisis, pues equivale a pretender que pueda celebrarse un verdadero matrimonio a espaldas del Estado, y que, al mismo tiempo, pueda éste imponerle reglamentaciones que irían en contra de su rasgo esencial, que no es otro que el de ser una unión libre.

Para algunos, hoy este fallo podría resultar aberrante por el trato discriminatorio, mientras que para otros puede tratarse simplemente una situación legal entre unos y otros. Las opiniones siempre estarán divididas, y aún los fallos de las Honorables Cortes pueden resultar contradictorios, teniendo en cuenta el estatus del que carecía la familia natural antes de la Constitución de 1991 y sus efectos posteriores que se vieron reflejados en la misma Constitución y en la Ley 54 de 1990 con sus reformas hasta la fecha. Desde tiempos pasados se ha escrito mucho sobre la familia y su connotación sociojurídica; sin embargo, en Colombia la familia conformada por vínculos naturales sólo logró un reconocimiento parcial con la Ley 54 de 1990, ley que nació huérfana pese a que en las Altas Cortes, juristas y expertos ya reconocían y dignificaban en sus escritos la unión marital de hecho como un estado civil, y al hablar de estado civil, la Corte Suprema de Justicia ${ }^{7}$ refiriéndose a la unión marital de hecho, expresa:

6 Ver Corte Constitucional de Colombia. Sentencia C-239 de 1994. (M.P. Jorge Arango Mejía: Mayo 19 de 1994).

7 Corte Suprema de Justicia - Sala de Casación Civil. M.P. Jaime Alberto 
[...] De lo dicho se sigue que la unión marital de hecho, al igual que el matrimonio, es una especie de estado civil, pues aparte de no ser una relación cualquiera, no es algo que sea externo a las personas que la conforman, por el contrario, trasciende a ellas, es decir, a la pareja misma y a cada uno de sus miembros individualmente considerados, con cierto estatus jurídico.

Como se puede ver, en esta sentencia la Corte ya reconoce el estado civil para estas uniones, apoyándose en el texto Lecciones de derecho civil, de los Hermanos Mazeaud (1959), ${ }^{8}$ que en su sección segunda "El estado civil de las personas", expresa: "El estado civil de una persona es su situación jurídica. El estado civil está pues unido a la persona, como la sombra al cuerpo. Más estrechamente todavía. Es la imagen jurídica de la persona [...]”.

Así, el problema objeto de esta investigación es detectar en la jurisprudencia de las tres Altas Cortes - desde la óptica de la familia como máxima expresión del ser humano ${ }^{9}$ y el derecho a la igualdad - cuáles son las diferenciaciones y la discriminación a parejas homosexuales y heterosexuales, a lo largo del precedente jurisprudencial. Es importante aclarar que aquí no se pierde el sentir, ni se desconoce la intención del Constituyente, reflejada en la jurisprudencia de 1991, que proscribe toda forma de discriminación y exclusión.

\section{Diseño METODOLÓGICO}

Esta investigación toma como fuente primordial la obra El derecho de los jueces, ${ }^{10}$ de Diego Eduardo López Medina (2006). La construcción de la línea jurisprudencial que se propone busca, además, y como lo ha sostenido Perelman en su nueva retórica y lógica jurídica, mostrar los juicios de valor que justifican sus decisiones jurídicas y ratio decidendi. Para esto, López Medina ${ }^{11}$ nos

Arrubla Paucar. Bogotá, D.C., dieciocho (18) de junio del dos mil ocho (2008). Ref: C-0500131100062004-00205-01.

8 Ver H. Mazeaud \& J. Mazeaud. (1959). El estado civil de las personas: caracteres del estado civil. H. y C. Mazeaud \& J. Mazeaud. Lecciones de derecho civil. Parte I. Vol. II. Los sujetos de derechos, las personas. Pág. 33. Ediciones Jurídicas Europea-A.M.

9 Ver Carlos Fradique Méndez. La familia frente a la ley y la vida. http:// www.acj.org.co/o/activ_acad.php?mod=posesion $\% 20$ fradique $\% 20$ mendez. Enero 2012. "La Familia es la primera escuela y universidad del ser Humano". "La Familia no es solamente un tema jurídico, es la vida en sus más altas manifestaciones de los pueblos".

10 Diego Eduardo López Medina. El derecho de los jueces. Legis. (2006).

11 Diego Eduardo López Medina cursó sus estudios universitarios en la Pontificia Universidad Javeriana de Bogotá, donde se graduó como abo- presenta unas técnicas argumentativas consistentes en el estudio del discurrir de la cultura jurídica colombiana, cuyo principal objeto de investigación es el precedente judicial y el papel de la jurisprudencia nacional a partir de la Constitución de 1991. La línea jurisprudencial que comenzará en el siguiente capítulo se ha construido con base en el siguiente orden: la gráfica del problema jurídico, la tipología y las tesis de sentencias, y por último se presentarán unas conclusiones generales de la línea.

\section{ANÁLISIS JURISPRUDENCIAL}

\section{A. Punto arquimédico de apoyo}

Tratándose del derecho a la igualdad, se puede afirmar que la jurisprudencia ha sido prolífera, por cuanto es uno de los derechos fundamentales aplicables a la mayoría de problemas jurídicos vistos en casi todos los hechos y actos jurídicos de la sociedad y, por ende, de la familia, cobrando especial importancia en uniones maritales de hecho. Para comenzar el análisis del problema jurídico expuesto en la tabla 1, se han escogido dos de los últimos pronunciamientos como puntos arquimédicos de apoyo, los cuales, aunque exteriorizan el tema del derecho a la igualdad con absoluto rigor, difieren en sus problemas y son determinantes para la argumentación que se propone. Entre los aspectos importantes que tocan, se tiene:

- Contenido y alcance de la vocación sucesoral de compañeros permanentes supérstites en uniones de hecho integradas por parejas heterosexuales y homosexuales.

- Porción conyugal: extensión de reconocimiento a compañeros permanentes y exclusión de reconocimiento a parejas del mismo sexo.

gado y filósofo. Con posterioridad, el profesor López Medina completó su formación académica en la Universidad de Harvard en los Estados Unidos, donde recibió sus títulos de maestría y doctorado en derecho. El profesor López fue distinguido con la medalla al mérito académico "Andres Bello", conferida por el Ministerio de Educación Nacional de Colombia. Actualmente reside en Colombia y ejerce la docencia y la investigación en la Universidad de los Andes y Universidad Nacional de Colombia. Sus principales obras son El derecho de los jueces y Teoría impura del derecho. Biografía online tomada de: Juris Pedia: el derecho compartido. [Citado 30 de Julio del 2011] Disponible en Internet: http://es.jurispedia.org/index.php/Lopez_Medina,_Diego_Eduardo 
Tabla 1. Línea jurisprudencial unión marital de hecho

\begin{tabular}{|c|c|c|c|}
\hline \multicolumn{4}{|c|}{$\begin{array}{l}\text { Problema jurídico } \\
\text { ¿Debe existir igualdad y por tanto no discriminación entre las parejas conformadas mediante unión marital de hecho y matrimonio, en cuanto a } \\
\text { sus derechos, forma de consagración como estado civil de la persona, sustitución pensional y todas las demás prerrogativas que de las dos institu- } \\
\text { ciones puedan concederse? }\end{array}$} \\
\hline Tesis A & & & Tesis B \\
\hline \multirow{12}{*}{$\begin{array}{l}\text { Debe existir igualdad, pues son } \\
\text { instituciones igualmente confor- } \\
\text { madoras de familia y protegidas } \\
\text { por la Constitución y la ley. } \\
\text { Los derechos consagrados como } \\
\text { estado civil, sustitución pensional } \\
\text { y todas las demás prerrogativas } \\
\text { deben ser idénticas tanto para el } \\
\text { cónyuge como para el compañero } \\
\text { permanente. }\end{array}$} & $\begin{array}{l}\text { Corte Constitucional de Colombia } \\
\text { Sentencia C-875 del } 2005 \\
\text { Agosto } 23 \text { del } 2005\end{array}$ & $\begin{array}{l}\text { Corte Suprema de Justicia } \\
\text { Agosto } 9 \text { del } 2005 \\
\text { Exp. No. } 11001-31-10-015- \\
\text { 1999-00482-01 }\end{array}$ & \multirow{12}{*}{$\begin{array}{l}\text { No debe existir igualdad, pues } \\
\text { pese a ser instituciones confor- } \\
\text { madoras de familia, difieren en } \\
\text { su regulación y no son absoluta- } \\
\text { mente semejantes, por la manera } \\
\text { como surgen a la vida jurídica } \\
\text { y por las reglas que desarrollan } \\
\text { estas dos instituciones. }\end{array}$} \\
\hline & $\begin{array}{l}\text { Consejo de Estado } \\
\text { Mayo } 8 \text { del } 2006 \\
\text { Rad: } 05001-23-31-000-2005- \\
08338-01(\text { AC) }\end{array}$ & & \\
\hline & $\begin{array}{l}\text { Corte Constitucional de Colombia } \\
\text { Sentencia C-075 del } 2007 \\
\text { Ref. Expediente D-6362 } \\
\text { Febrero } 7 \text { del } 2007\end{array}$ & $\begin{array}{l}\text { Corte Suprema de Justicia } \\
\text { Marzo } 21 \text { del } 2006 \\
\text { Expediente No. 11001-02-03- } \\
000-2005-016\end{array}$ & \\
\hline & $\begin{array}{l}\text { Corte Constitucional de Colombia } \\
\text { Sentencia C-521 del } 2007 \\
\text { Julio } 11 \text { del } 2007\end{array}$ & & \\
\hline & $\begin{array}{l}\text { Corte Suprema de Justicia } \\
\text { Junio } 18 \text { del } 2008 \\
\text { Exp. No C-0500131100062004- } \\
\text { 00205-01 }\end{array}$ & & \\
\hline & $\begin{array}{l}\text { Corte constitucional. Sentencia } \\
\text { t- } 847 / 08 \text { veintiocho }(28) \text { de agosto } \\
\text { del dos mil ocho }(2008) \text {. }\end{array}$ & & \\
\hline & $\begin{array}{l}\text { Corte suprema de justicia .once } \\
\text { de noviembre del dos mil ocho } \\
\text { expediente. no. 11001-02-03-000- } \\
\text { 2008-01484-01 }\end{array}$ & & \\
\hline & $\begin{array}{l}\text { Corte suprema de justicia .ref.: } \\
\text { 85001-3184-001-2002-00197-01 } \\
\text { once (11) de marzo del dos mil } \\
\text { nueve (2009) }\end{array}$ & & \\
\hline & $\begin{array}{l}\text { Consejo de estado. veintiocho (28) } \\
\text { de abril del dos mil once (2011). } \\
\text { radicación número: 19001-23-31- } \\
000-2010-00237-01(\mathrm{ac})\end{array}$ & & \\
\hline & $\begin{array}{l}\text { Corte Constitucional de Colombia } \\
\text { Sentencia T-403 del } 2011 \\
\text { Mayo } 17 \text { del } 2011\end{array}$ & & \\
\hline & $\begin{array}{l}\text { Corte Constitucional de Colombia } \\
\text { Sentencia C- } 283 \text { del } 2011 \\
\text { Ref. Expediente D- } 8112 \\
\text { M.P. Jorge Ignacio Pretelt Chaljub } \\
\text { Abril } 13 \text { del } 2011\end{array}$ & & \\
\hline & $\begin{array}{l}\text { Corte Constitucional de Colombia } \\
\text { Sentencia C-238 del } 2012 \\
\text { Marzo } 22 \text { del } 2012\end{array}$ & & \\
\hline
\end{tabular}

Fuente. Elaboración propia 
La primera sentencia a analizar se presenta en el gráfico 1 .

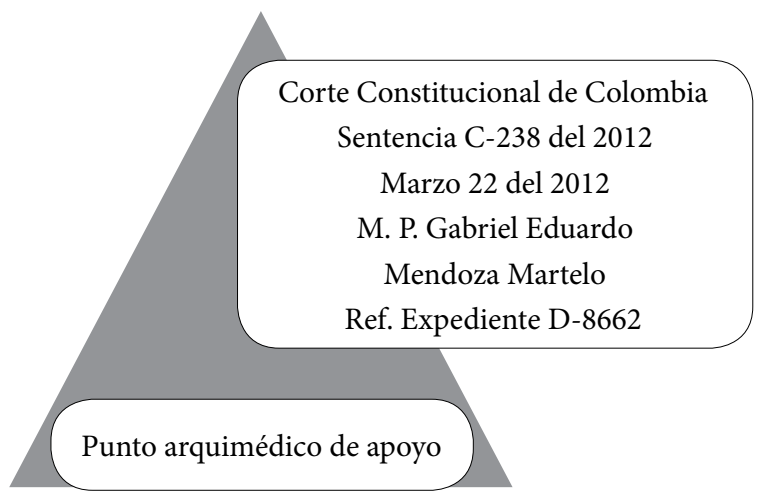

Gráfico 1. Punto arquimédico de la Sentencia C-238 del 2012 Fuente. Elaboración propia

La modulación de esta sentencia se define en la demanda de constitucionalidad de normas relativas a la sucesión intestada y a la porción conyugal que contempla como beneficiario únicamente al cónyuge omitiendo a compañeros permanentes. ${ }^{12}$ Se analiza el origen de la familia reiterando que, independientemente de la forma de constituirse la unión, ya sea libre, o por vínculo de matrimonio, se configura una familia. La H. Corte insiste en los postulados de igualdad y no discriminación hacia los compañeros permanentes para concluir que en beneficios herenciales y vocación hereditaria no es el contrato de matrimonio u otro semejante lo que hace beneficiaria a la persona a heredar, sino que es la relación de familia que se tenga con el causante. Considera que así como existen criterios que implican diferenciación entre las dos uniones, también los hay que comportan similitud, por lo cual no hay lugar a aceptar un trato diverso. En este fallo se hace especial alusión a la vocación sucesoral, reiterando que esta obedece a un criterio familiar en el que todos sus miembros son protegidos constitucionalmente para este fin. ${ }^{13}$ Igualmen-

12 Demanda de constitucionalidad en contra de la expresión "cónyuge" contenida en los artículos 1040, 1046, 1047 y 1233 del Código Civil.

13 "Si como lo ha sostenido la Corte Constitucional el amor, el respeto, la comprensión y la solidaridad que unen a los cónyuges y a los compañeros permanentes son, en muchos casos, más fuertes y sólidos que los existentes entre consanguíneos, es más razonable que, para efectos sucesorales, sean equiparados los compañeros a los cónyuges que permitir que, por excluir al compañero permanente, los tíos o los sobrinos del causante recojan una herencia, pese a la alta probabilidad de que su vínculo con el causante no sea tan intenso como el que, en condiciones te se reconocen aquí los derechos de parejas del mismo sexo, con sustento en el Art. 1233 del C.C. Sin embargo, argumenta la Corte, que como no todas las situaciones ameritan la igualdad de trato, se precisa que cuando se pretenda el derecho a la igualdad dispensado al cónyuge, frente al que debe conferirse al compañero permanente, es menester demostrar que las situaciones son equiparables, no obstante reconocerse los derechos patrimoniales a los compañeros permanentes, en el entendido de que es una forma de equilibrar las cargas para aquellos que comparten una vida en común, libertad de compartir proyecto de vida, prodigándose solidaridad, cuidado y apoyo mutuo, aspectos que no son válidos predicarse solamente a los cónyuges.

La Sentencia C-283 del 2011 constituye la segunda sentencia hito a analizar, y se presenta en el gráfico 2 .

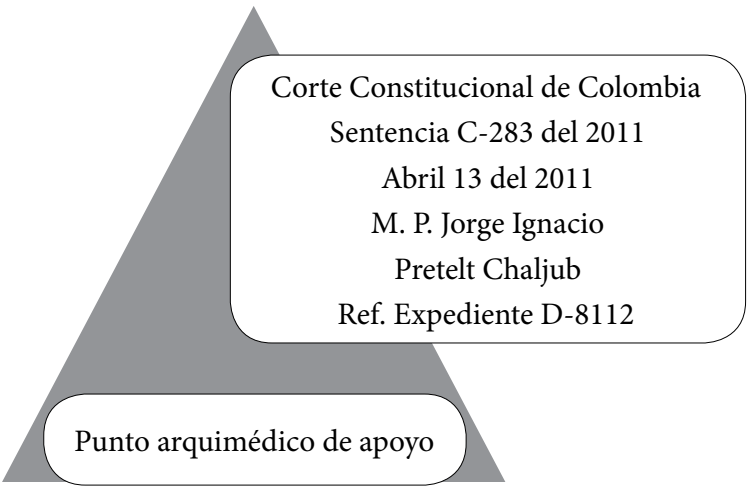

Gráfico 2. Punto arquimédico de la Sentencia C-283 del 2011 Fuente. Elaboración propia

Esta sentencia de constitucionalidad, ${ }^{14}$ una de las más importantes escogidas para este análisis, es el ejemplo más claro de ingeniería de reversa para el tema que nos ocupa, no sólo porque recoge la jurisprudencia de las últimas décadas, sino porque realiza un análisis de la Sentencia hito C-174 de $1996^{15}$ en la que se

normales, se establece con la persona con quien se comparte un proyecto de vida.

El compartir un proyecto de vida suele implicar, además, la contribución del compañero permanente en el mantenimiento y hasta en el acrecentamiento del patrimonio personal del miembro de la pareja, razón de más que justifica que en materia sucesoral la protección de la familia comprenda al compañero o compañera permanente del causante, de la misma manera como comprende al cónyuge supérstite. Ver Corte Constitucional de Colombia. Sentencia C-238 del 2012. (M.P. Gabriel Eduardo Mendoza Martelo: Marzo 22 del 2012).

14 Demanda de inconstitucionalidad contra los artículos 1016-5. 1045, $1054,1226,1230,1231,1232,1234,1235,1236,1237,1238,1243,1248$, 1249, 1251 y 1278 del Código Civil.

15 Ver Corte Constitucional de Colombia. Sentencia C-174 de 1996. (M.P. Jorge Arango Mejía: Abril 29 de 1996). 
declara la exequibilidad sin condicionamiento de algunos de los artículos, que precisamente son el objeto de la C-283 del 2011. En esta se consideran las razones inobjetables de la legislación que ampara a los compañeros permanentes para acceder a la porción conyugal. La Corte rechaza el condicionamiento de tener un vínculo matrimonial para gozar de este derecho y, en este sentido, se examinan los fines de la porción conyugal como garantía patrimonial ${ }^{16}$ afirmando y reiterando quiénes son los titulares de este derecho, en los que obviamente no se excluye al compañero permanente. Igualmente, y de forma por lo demás muy pedagógica, se realiza en esta sentencia un estudio hermenéutico muy preciso sobre la cosa juzgada respecto a la porción conyugal, y explica cómo - debido a los cambios sustanciales en las relaciones familiares que han ameritado modificaciones trascendentales en la jurisprudencia- se ha dado un giro al orden jurídico nacional. En este sentido cobra gran importancia para este análisis la Sentencia C-174 de 1996 por tratarse de los mismos artículos que se demandan en la sentencia del 2011. Haciendo alusión a la Sentencia C-174 de 1996, encontramos que la H. Corte hace una distinción del régimen legal del cónyuge y compañero permanente, para lo cual expresan una diferenciación así:

[...] Tercera.- Algunas reflexiones sobre el matrimonio y la unión libre, a la luz de la Constitución.

\footnotetext{
16 "La porción conyugal está definida como aquella parte del patrimonio de una persona difunta que la ley asigna al cónyuge sobreviviente que carece de lo necesario para su congrua subsistencia, asignación que no es a título de heredero, pues su condición jurídica es diversa de la de éste, y que más que una prestación de carácter alimenticio basada en un criterio de necesidad, es una figura de naturaleza compensatoria, para afectar el patrimonio del causante a través de una asignación forzosa que le permite al supérstite contar con un patrimonio adecuado teniendo como referente el patrimonio del cónyuge fallecido. Es una especie de crédito a cargo de la sucesión. Son características de la porción conyugal: (i) tiene como beneficiario al cónyuge sobreviviente, independientemente del sexo; (ii) no está sujeta a un monto determinado, toda vez que depende del patrimonio del cónyuge fallecido; (iii) lo que se recibe por este concepto pasa a incorporar el patrimonio del sujeto a favor de quien se reconoce; (iv) no está atada a la inexistencia de patrimonio del sobreviviente; sólo se requiere que lo que éste pueda percibir por otros conceptos sea o resulte inferior a la porción conyugal para que nazca del derecho a percibirla; (v) Este derecho se concreta al tiempo en que se abre la sucesión. Por tanto, si el cónyuge sobreviviente no tiene bienes en ese momento, o los que posee son de inferior valor, adquiere el derecho a la porción, sin importar que posteriormente adquiera otros. Por el contrario, si posee bienes de mayor valor y después los pierde o su valor disminuye, no tendrá derecho a dicha porción, tal como se desprende de una lectura de los artículos 1232 y 1233 del Código Civil". Ver Corte Constitucional de Colombia. Sentencia C-283 del 2011. (M.P. Jorge Ignacio Pretelt Chaljub: Abril 13 del 2011).
}

Es verdad que en el artículo 42 de la Constitución, se reconoció que la familia se constituye "por vínculos naturales o jurídicos, por la decisión libre de un hombre y una mujer de contraer matrimonio o por la voluntad responsable de conformarla". Pero de ahí a sostener que la Constitución estableció la igualdad entre el matrimonio y la unión libre, hay mucha distancia. El matrimonio es diferente de la unión libre, y, por lo mismo, difieren entre sí las situaciones jurídicas de los cónyuges y de los compañeros permanentes. (Cursivas propias).

[...] Sea lo primero decir que es erróneo sostener, como parece hacerlo el demandante, que la Constitución consagre la absoluta igualdad entre el matrimonio y la unión libre, o unión marital de hecho, como la denomina la ley 54 de 1990. Basta leer el artículo 42 de la Constitución para entender por qué no es así. (Cursivas propias).

Veamos qué dice la Sentencia C-283 del 2011, objeto de la misma demanda, acerca de algunos de los artículos del Código Civil previstos anteriormente:

[...] Principio de igualdad consagrado en el artículo 13 de la Constitución Política: las normas acusadas resultan discriminatorias al reconocer porción conyugal a los cónyuges y no a los compañeros permanentes que dentro de las uniones maritales de hecho también tienen la voluntad y capacidad de constituir familia, y como tal tienen derecho a que se les reconozca los derechos reconocidos a los miembros de las personas unidas por un vínculo matrimonial. Por tanto, las parejas heterosexuales como homosexuales deben ser beneficiarias de la denominada "porción conyugal" para hacer realizable el principio de la igualdad.

Para algunos podrían resultar contradictorios los razonamientos de la $\mathrm{H}$. Corte, por cuanto en la primera sentencia no se hizo un examen del derecho a la igualdad-tal como lo demandó el actor-, sino que se realizó una diferenciación entre los dos tipos de uniones, para terminar 15 años después admitiendo los argumentos que fueron rechazados. Sin embargo, la Corte explica el porqué del cambio en sus posiciones, argumentos que finalmente serán los lectores quienes los calificarán. ${ }^{17}$

\footnotetext{
17 Ídem. "Si bien mediante Sentencia C-174 de 1996 esta Corporación declaró la exequibilidad, sin ningún condicionamiento, de algunos de los artículos que son ahora nuevamente objeto de demanda, no puede afirmarse que haya operado la cosa juzgada constitucional, en primer lugar, por cuanto la decisión adoptada se basó exclusivamente en una comparación de la forma como surgen a la vida jurídica las instituciones del matrimonio y la unión marital de hecho y las normas a las que se sujetan, pero en ella se omitió un análisis finalístico de la institución de
} 


\section{Sentencias hito}

\section{- 1.1. Sentencia hito $N^{o} 1$}

Corte Suprema de Justicia

M.P. Silvio Fernando Trejos Bueno

Agosto 9 del 2005

Ref. Expediente No. 11001-31-10-015-1999-00482-01

Se considera como fundadora de línea esta sentencia en la cual se debate el estado civil del compañero permanente, producto de la unión marital de hecho. Aquí la Corte Suprema de Justicia hace una reseña de fallos en los que se aparta e inadmite una posible igualdad entre las dos uniones. ${ }^{18}$ Para la Corte, la consagración constitucional otorgada en virtud del art. 42 a la familia, no es suficiente para equiparar la unión marital de hecho y el matrimonio, por cuanto carece de reglamentación, y el enunciado de este precepto constitucional es huérfano legalmente; considera que es la ley la que debe determinar lo relativo al estado civil de las personas, aduciendo dicha orfandad desde la Ley 54 de 1990. Para la Corte, el reconocimiento de la unión por vínculos naturales exige una regulación legal como estado civil por la situación jurídica de la persona ante

la "porción conyugal" en estos dos escenarios; y en segundo lugar, por lo que tiene que ver con lo que la jurisprudencia ha denominado cambio del contexto normativo, concepto que hace referencia a los cambios que se presentan en la sociedad de los cuales debe ser consciente el juez constitucional para efectuar un nuevo análisis sobre normas que fueron consideradas exequibles en un tiempo pero que a la luz de la nueva realidad pueden no serlo. Es así que entre la declaración de exequibilidad de las normas del código civil relativas a la porción conyugal, esta Corporación ha proferido un sinnúmero de providencias que han tenido como fin principal extender algunos de los derechos, las garantías y los beneficios que la legislación civil reconoce de tiempo atrás a los cónyuges a las compañeras y compañeros permanentes, bajo el supuesto que si bien las dos uniones son diferentes en cuanto a la forma que nacen a la vida jurídica, ello no obsta para reconocer que ellas tienen unas similitudes que obligan al legislador a dar un trato por lo menos similar a una y otra, en aquellos aspectos que se derivan de la relación de pareja, de la relación con sus hijos y frente a los aspectos patrimoniales, entre otros. En este orden de ideas, se considera que, en el presente caso, (i) en tanto el fallo anterior no efectuó el análisis propuesto ahora por el demandante y (ii) el contexto normativo ha variado, es posible afirmar que no ha operado el fenómeno de la cosa juzgada constitucional".

18 La Corte dijo: "En el ordenamiento jurídico colombiano no se ha establecido constitucional, ni legalmente, el estado civil de compañero permanente derivado de la unión marital de hecho. En efecto, no se puede deducir semejante consagración de lo dispuesto por el artículo 42 de la Constitución Política, por el hecho de que en él se diga que la familia "se constituye por vínculos naturales o jurídicos, por la decisión de un hombre y una mujer de contraer matrimonio o por la voluntad responsable de conformarla", aspecto éste, aquí subrayado, que corresponde a un mero enunciado, huérfano aún de reglamentación legal". Ver Corte Suprema de Justicia de Colombia. Auto del 28 de noviembre del 2001. (Expediente 1999-482). la familia y la sociedad, que tiene connotación de indivisible, indisponible e imprescriptible necesariamente asignada por la ley.

- 1.2. Sentencia hito $N^{\circ} 2$

Corte Suprema de Justicia

M.P. Jaime Alberto Arrubla Paucar

Junio 18 del 2008

Ref. Expediente No. C-0500131100062004-00205-01

Esta sentencia marca un hito importante en la historia jurisprudencial que cobija las uniones maritales de hecho, ya que se aparta por completo de las consideraciones hechas en la jurisprudencia anterior y viene a ponerle fin a un conflicto en las Cortes en virtud del Recurso Extraordinario de Casación que sólo era admitido siguiendo taxativamente el art. 366 del CPC. ${ }^{19}$ Así, mediante este pronunciamiento se decide sobre la admisión del recurso extraordinario de casación y, por ende, de la declaratoria del estado civil para parejas unidas por vínculos naturales, en el entendido de que así como el matrimonio origina estado civil de casado, la unión marital de hecho también genera el de "compañero o compañera permanente", pues así lo estipulo la Ley 54 de 1990, la cual no se limita a definir el fenómeno natural ni a señalar sus elementos, sino que precisa en su definición a los compañeros permanentes el término "para todos los efectos civiles". ${ }^{20}$ Finalmente, la Corte Suprema de Justicia acoge la posición garantista sustentada en los cambios sociales, e incluso legales, en los que es

19 Ver Código de Procedimiento Civil [CPC]. Decretos número 1400 y 2019 de 1970. Agosto 6 y Octubre 26 de 1970 (Colombia): "Casación. Artículo 366. Procedencia. El recurso de casación procede contra las siguientes sentencias dictadas en segunda instancia por los tribunales superiores, cuando el valor actual de la resolución desfavorable al recurrente sea o exceda de cuatrocientos veinticinco (425) salarios mínimos legales mensuales vigentes así: [...] 4. Las sentencias de segundo grado dictadas por los tribunales superiores en procesos ordinarios ${ }^{\star}$ que versen sobre el estado civil, y contra las que profieran en única instancia en procesos sobre responsabilidad civil de los jueces que trata el artículo 40 ".

20 Es de verse, sin embargo, que un nuevo análisis de la cuestión demanda rectificar la doctrina sobre el particular, porque aun sin que se haya expedido la ley que haga la asignación que en tales antecedentes se echó de menos, normativamente se han introducido cambios que tienden a darle a la unión marital de hecho un tratamiento jurídico equiparable o semejante al del matrimonio y a todo lo que gira alrededor de esas situaciones, cuestiones todas que sin lugar a dudas permiten subsumir a aquélla en la definición del artículo $1^{\circ}$ del Decreto 1260 de 1970, según el cual el "estado civil de una persona es su situación jurídica en la familia y la sociedad, determina su capacidad para ejercer ciertos derechos y contraer ciertas obligaciones, es indivisible, indisponible e imprescriptible y su asignación corresponde a la ley". Ver Corte Suprema de Justicia. Sala de Casación Civil. Proceso 2004-205. (M.P. Jaime Alberto Arrubla Paucar: Junio 18 del 2008). 
necesario equiparar la unión marital de hecho al matrimonio, y define que la unión marital de hecho constituye un estado civil, lo que en términos de la misma Corte era inadmisible.

\section{- 1.3. Sentencia fundadora de línea}

Corte Constitucional de Colombia

Sentencia C-875 del 2005

M.P. Rodrigo Escobar Gil

Agosto 23 del 2005

Es una Sentencia en la que la Corte Constitucional considera igualitaria la unión marital de hecho y el matrimonio como instituciones creadoras de familia, se discute acerca de la posible discriminación que existe ante los beneficios tributarios que son otorgados a los cónyuges y no a los compañeros permanentes para así la Corte concluir que estos beneficios deben extenderse a las parejas unidas por vínculo natural, en virtud del derecho a la igualdad y no discriminación por razones de origen familiar; enfatiza en que la libertad de configuración del legislador no da la potestad de que este incurra en estas discriminaciones.

- 1.4. Sentencia hito confirmatoria de línea

Corte Constitucional de Colombia

Sentencia C-075 del 2007

M.P. Rodrigo Escobar Gil

Febrero 7 del 2007

Ref.: Expediente D-6362

Puede decirse que para el problema jurídico planteado esta sentencia ${ }^{21}$ - considerada determinanteha marcado la diferencia en el ámbito jurídico nacional, y que sin duda es el precedente que marcará hito en la historia jurisprudencial colombiana, a la vez que ha sido objeto de grandes controversias y manifestaciones desde los diferentes sectores del Estado. En ella se definen los derechos patrimoniales de las parejas del mismo sexo, lo mismo que la protección del régimen patrimonial de los compañeros permanentes, la no exclusión de parejas homosexuales a estos derechos y un análisis de fondo sobre la necesidad de una integración de unidad normativa, teniendo en cuenta que la norma sólo contemplaba los derechos para parejas heterosexuales. Esta sentencia ilustra magistralmente el derecho a la igualdad, haciendo un examen minucioso del test estricto de igualdad, en el que se trae al escenario la línea

21 Ver Corte Constitucional de Colombia. Sentencia C-075 del 2007. (M.P. Rodrigo Escobar Gil: Febrero 7 del 2007). jurisprudencial reiterada y reafirmada por la $\mathrm{H}$. Corte en el que queda proscrita toda forma de discriminación en razón a la orientación sexual, y hace un llamado a los diferentes grupos del conglomerado social para atender los lineamientos constitucionales y para definir medidas para su protección, en el entendido de que esta protección está ligada directamente con la dignidad humana. ${ }^{22}$

\section{Sentencias confirmatorias de línea}

A continuación se esbozará un resumen de las tesis seleccionadas para el problema jurídico, y al final se realizarán las conclusiones de estas, teniendo en cuenta cada Corte en particular.

\section{- 2.1. Corte Suprema de Justicia - Sala de Casación Civil \\ M.P. César Julio Valencia Copete \\ Marzo 21 del 2006 \\ Ref. Expediente No. 11001-02-03-000-2005-01672-00}

En esta sentencia se reitera lo expresado por la Corte Suprema de Justicia el 9 de agosto del 2005 afirmando que no se puede igualar el estado civil surgido del matrimonio con uno que aún no ha determinado la Ley, tal como es el que eventualmente podría existir a causa de la existencia de la unión marital de hecho. Esta sentencia aclara que,

22 Ídem. La jurisprudencia constitucional en Colombia, tanto en decisiones de tutela como de constitucionalidad, ha señalado que los homosexuales han sido un grupo tradicionalmente discriminado, pero que a la luz del ordenamiento superior toda diferencia de trato fundada en la orientación sexual de una persona se presume inconstitucional y se encuentra sometida a un control constitucional estricto. En ese contexto se ha señalado que "[d]entro del ámbito de la autonomía personal, la diversidad sexual está claramente protegida por la Constitución, precisamente porque la Carta, sin duda alguna, aspira a ser un marco jurídico en el cual puedan 'coexistir las más diversas formas de vida humana"'. [...]

Esta Corporación ha expresado que la dignidad humana es un valor superior y un principio fundante del Estado Social de Derecho, conforme al cual todas las personas deben recibir un trato acorde con su naturaleza humana. La Corte ha señalado que "[...] dentro del sistema constitucional colombiano, el principio de dignidad constituye el centro axiológico a partir del cual se derivan las obligaciones de protección, respeto y promoción de los derechos constitucionales y el aseguramiento del cumplimiento de los deberes constitucionales, bajo la égida del orden justo". Para la Corte, "[p]or dignidad se entiende la supremacía que ostenta la persona como atributo inherente a su ser racional, cuya valoración y reconocimiento no puede estimarse como la causa o el efecto de alguien o de algo (es decir, como objeto), sino como un fin superior que subyace en sí mismo", 
[...] si bien es cierto que en la unión marital de hecho existen derechos y obligaciones, incluso algunos similares a los que se pregonan de quienes son marido y mujer en el matrimonio, lo cierto es que a términos de la propia Constitución (artículo 42, inciso 13) es la ley la llamada a determinar "lo relativo al estado civil de las personas y los consiguientes derechos y deberes", y ocurre que las uniones que se comentan, por más regulares y estables que resulten ser, no han sido concebidas por el legislador colombiano como constitutivas de un estado determinado, toda vez que aquel estatuto jurídico no contiene norma alguna a través de la cual ello pueda inferirse.

\section{- 2.2. Consejo de Estado - Sala de lo Contencioso-} Administrativo

Consejero ponente: Camilo Arciniegas Andrade

Mayo 8 del 2006

Radicación No. 05001-23-31-000-2005-08338-01(AC)

En este fallo de tutela, el Consejo de Estado determina que sí hubo una discriminación respecto de la compañera permanente quien ya había comprobado mediante sentencia judicial que tenía tal calidad. Sin embargo, la entidad demandada quería imponerle una carga no establecida legalmente, como era la apertura de la sucesión del causante, originando con esto una evidente discriminación hacia la compañera permanente afectada y vulnerada igualmente en sus derechos al mínimo vital.

\section{- 2.3. Corte Constitucional de Colombia}

Sentencia C-521 del 2007

M.P. Clara Inés Vargas Hernández

Julio 11 del 2007

En esta sentencia se evidencia uno de los flagelos que ha sido objeto de múltiples demandas por parte de los compañeros permanentes, como es la seguridad social, pues se demanda una disposición, por carecer de protección hacia ellos, dado que les exige el límite temporal de dos años para poder ser beneficiarios del compañero cotizante al sistema general de seguridad social en salud. Así pues, la Corte acoge los razonamientos suficientes para determinar que el artículo 163 (parcial) de la Ley 100 de 1993 es inconstitucional y decide retirar esta disposición del ordenamiento jurídico, indicando que el lapso de dos años que se exige para la declaración de la unión marital de hecho obedece a los efectos patrimoniales que pueden acaecer de esta, pero que este límite no debe fijarse para los derechos fundamentales que contiene la seguridad social, pues exigirle al compañero permanente que debe haber permanecido dos años en comunidad de vida permanente para gozar de tal beneficio, es una discriminación que atenta contra el derecho a la igualdad respecto a quienes se encuentran unidos por vínculo matrimonial.

\subsection{Corte Constitucional de Colombia}

Sentencia T-847 del 2008

M.P. Manuel José Cepeda Espinosa

Agosto 28 del 2008

Ref. Expediente No. T-1909727

En esta sentencia se observa cómo la entidad accionada se abstuvo de reconocer la pensión a la compañera permanente, hasta que se decidiera la demanda de declaración de la unión marital de hecho y la respectiva disolución y liquidación de la sociedad patrimonial, interpuesta por la misma actora; asimismo se observa cómo se transgrede el derecho a la igualdad, cuando las entidades imponen a la compañera permanente cargas que no debe soportar para acceder a la sustitución pensional, máxime en esta sentencia que se ve afectado el mínimo vital de la accionante y de su hija menor de edad. En el caso en concreto se encuentra que mientras se resuelve el litigio pendiente se está vulnerando el derecho al mínimo vital de la compañera permanente del causante, pues su subsistencia dependía del fallecido; además, se tiene en cuenta que en el núcleo familiar hay una menor de edad, por ende el perjuicio a que se ve sometida esta familia se refleja notoriamente siendo procedente la concesión del amparo solicitado.

\section{- 2.5. Corte Suprema de Justicia - Sala de Casación Civil M.P. Edgardo Villamil Portilla \\ Noviembre 11 del 2008 \\ Expediente. No. 11001-02-03-000-2008-01484-01}

Esta es la segunda sentencia proferida por la Corte Suprema de Justicia en la que, bajo criterios de igualdad, evolución social y normativa esta Corporación plantea que la unión marital de hecho sí constituye estado civil para la persona y, por ende, así como existe el estado civil de casado o soltero, también existe el de compañera o compañero permanente y por esto mismo es susceptible acorde con la naturaleza del asunto de admitirse en un eventual recurso de casación.

\footnotetext{
- 2.6. Corte Suprema de Justicia - Sala de Casación Civil M.P. William Namén Vargas

Marzo 11 del 2009

Ref. Exp. No. 85001-3184-001-2002-00197-01
} 
De la lectura de esta sentencia puede deducirse que la situación de secuestro no constituye causal alguna que marque pauta para empezar a correr el término de prescripción contemplado para la declaración de unión marital de hecho, ${ }^{23}$ toda vez que ni la Ley 54/90 ni la Ley 986/2005 lo estipulan. Para la Corte, la unión marital de hecho entre compañeros permanentes en cuanto se refiere a un estado civil es imprescriptible, no así lo concerniente a la declaración judicial de existencia de sociedad patrimonial derivada de la unión marital que sí es prescriptible. En este orden de ideas, el caso concreto de esta sentencia que obedece a un caso de secuestro, considera la Corte, que se vulneran los derechos humanos a la libertad, la integridad y seguridad personales, inspirada en la salvaguardia de los secuestrados y su núcleo familiar, inspirada en la declaración de derechos humanos y plasmada en la Ley 986 del 2005, que protege a los compañeros permanentes, como quiera que para el caso específico es una protección que se extiende a la familia del secuestrado. ${ }^{24}$

\section{- 2.7. Consejo de Estado - Sala de lo Contencioso- Administrativo}

Consejera ponente: María Elizabeth García González Abril 28 del 2011

Radicación No. 19001-23-31-000-2010-00237-01(AC)

Según la selección de sentencias, esta se configura como sentencia confirmatoria, pues ratifica que al momento de reclamar la sustitución pensional las entidades administrativas no pueden exigirle a la compañera permanente ciertas cargas que incluso se encuentran

23 En sentir del juzgador de segunda instancia, "el demandante disponía del plazo corto y objetivo de un año, para promover las acciones encaminadas a obtener la declaración judicial de existencia de sociedad patrimonial de bienes entre compañeros permanentes, así como para pedir la disolución y liquidación de la misma" al tenor del artículo $8^{\circ}$ de la Ley 54 de 1990 consagratorio de una "prescripción" de corta duración, objetiva e interrumpible con la presentación de la demanda, siendo inaplicable el artículo 13 de la Ley 986 del 2005 en torno de la interrupción de plazos y términos, por tratarse de una norma favorable sólo a la secuestrada, no susceptible de invocación sino por ésta y no por el demandante para interrumpir el término prescriptivo. Ver Corte Suprema de Justicia. Sala de Casación Civil. Proceso 2002-197. (M.P. William Namén Vargas: Marzo 11 del 2009).

24 Por tanto, en el caso específico de la unión marital de hecho, contemplando esta ley la protección, también para el núcleo familiar del secuestrado, cuando quiera que fuere menester para tales efectos o para los consagrados en el ordenamiento, la declaración judicial de existencia de la unión marital, pueden promoverse las acciones y los procesos al respecto, pues, de otra manera, negar esta posibilidad, lisa y llanamente conduce a infirmar sus propósitos y finalidades tutelares singulares. superiores a lo establecido en la ley, pues se vulneraría el derecho a la igualdad, como es el caso en que se suspende el pago de la pensión de sobrevivientes con el pretexto de que no se ha aportado a la entidad demandada el documento que acredite la declaración de la unión marital de hecho ante la autoridad competente. Asimismo, reitera que una cosa es la sentencia que declare la unión marital de hecho para sus consecuentes efectos patrimoniales, y otra la mera convivencia que debe acreditarse con el fin de que la compañera permanente obtenga el derecho a la sustitución pensional.

\section{- 2.8. Corte Constitucional de Colombia \\ Sentencia T-403 del 2011 \\ M.P. Gabriel Eduardo Mendoza Martelo \\ Mayo 17 del 2011}

De acuerdo con el asunto examinado en esta sentencia, puede considerarse que la Corte Constitucional es clara al determinar que la familia constituida por vínculos naturales o por vínculos jurídicos merece igual protección y no discriminación, tal como lo estipula nuestra Carta Política; asimismo, mediante esta Sentencia se recalca que esta protección debe extenderse a todos los miembros del grupo familiar, incluyendo por supuesto a los hijastros.

\section{Conclusiones DEL PROBLEMA JURÍDICO}

\section{A. Corte Suprema de Justicia}

La Corte Suprema de Justicia trata el tema de la igualdad únicamente respecto a las admisiones de recurso extraordinario de casación, en el que el foco de discusión se centró en un problema jurídico esencial: "si la unión marital de hecho puede llegar a constituir un estado civil", aspecto jurídico que atañe a la situación de la persona frente a la familia, la sociedad y el Estado. El argumento expuesto por la Corte es que era el poder legislativo el competente para examinar tal cuestión y si bien las dos instituciones tenían elementos comunes, por esto no se podían llegar al punto de ser concebidas como un estado civil. La sentencia del 18 de junio del 2008 (M.P. Jaime Alberto Arrubla Paucar), puede considerarse hito dentro del análisis jurisprudencial, ya que reconoce que la unión marital de hecho es un esta- 
do civil, como situación inherente de la persona frente al Estado la sociedad y la familia, teniendo en cuenta criterios de igualdad, evolución social y normativa.

\section{B. Corte Constitucional de Colombia}

Antes de concluir la posición de la H. Corte Constitucional a este problema jurídico, es necesario reconocer que esta alta corporación, como garante de derechos fundamentales en Colombia, en reiterados fallos ha abordado el tema del derecho a la igualdad y los mandatos que cobijan todos los actos y hechos jurídicos en el país.

La Corte Constitucional, además de reiterar la aplicación del principio a la igualdad a los compañeros permanentes, también ordena su aplicación general a todo el núcleo familiar individual y grupalmente considerado, en el entendido de que se debe extender a los hijos habidos en la unión marital de hecho y los hijos que existan en la familia que conformen los compañeros permanentes producto de uniones anteriores pero que conviven todos juntos, ya que estos deben ser considerados como hijastros que pertenecen al núcleo familiar y, por ende, deben ser tratados sin discriminación alguna. En virtud de las disposiciones constitucionales, la Corte manifiesta que cualquier regulación, emanada incluso de los actos administrativos, no puede estar empleando una desventaja respecto de unos miembros del grupo familiar.

Cabe resaltar las Sentencias C-075 del 2007, C-844 del 2010, C-283 del 2011 que en forma armonizada realizan una ingeniería de reversa con citas de fallos de últimas décadas en los que se plasma el derecho a la igualdad visto desde los diferentes escenarios y desde el derecho internacional de derechos humanos, reconociendo su no unificación en la norma. Es por esto que se busca en este problema jurídico ahondar en la dimensión de los derechos constitucionales que cobijan a los compañeros permanentes, tales como:

- La protección constitucional de la familia, independientemente de su origen.

- El derecho a la igualdad para parejas homosexuales $\mathrm{y}$ heterosexuales.

- Los derechos en materia prestacional.

- Los derechos en materia de seguridad social en pensiones y en salud.

- Los derechos en materia de obligaciones alimentarias.

- Los derechos en materia tributaria, entre otros.
Para concluir, respecto al derecho a la igualdad, se puede decir que gracias a la $\mathrm{H}$. Corte Constitucional, el ciudadano común puede sentirse satisfecho, porque poco a poco se han ido ponderando los derechos y las garantías de que son titulares. Esta alta corporación se reafirma cada vez más en la idea de no exclusión y no discriminación como el valor auténtico que sustenta la seguridad jurídica en su verdadera dimensión. El trato que la Corte le ha dado a los distintos tipos de familia se ha ido afianzando, y per se la familia es y será en el andamiaje jurisprudencial la piedra angular, cimiento para el análisis de otros problemas jurídicos que giran alrededor de la familia y que son parte de nuestra cotidianidad. En la Sentencia C-250 del $2012^{25}$ se resumen los mandatos que comprenden el derecho a la igualdad que es preciso traerlos como colofón para reflexionar sobre principio visto desde esta alta corporación.

Principio de igualdad. Mandatos que comprende. Del principio de igualdad pueden a su vez ser descompuestos en cuatro mandatos: (i) un mandato de trato idéntico a destinatarios que se encuentren en circunstancias idénticas, (ii) un mandato de trato enteramente diferenciado a destinatarios cuyas situaciones no comparten ningún elemento en común, (iii) un mandato de trato paritario a destinatarios cuyas situaciones presenten similitudes y diferencias, pero las similitudes sean más relevantes a pesar de las diferencias y, (iv) un mandato de trato diferenciado a destinatarios que se encuentren también en una posición en parte similar y en parte diversa, pero en cuyo caso las diferencias sean más relevantes que las similitudes. Estos cuatro contenidos tienen sustento en el artículo 13 constitucional, pues mientras el inciso primero del citado precepto señala la igualdad de protección, de trato y en el goce de derechos, libertades y oportunidades, al igual que la prohibición de discriminación, los incisos segundo y tercero contienen mandatos específicos de trato diferenciado a favor de ciertos grupos marginados, discriminados o especialmente vulnerables.

\section{Consejo de Estado}

En las sentencias estudiadas del Consejo de Estado, se observan casos en los que las compañeras permanentes no pueden acceder a seguridad social o a su sustitución

25 Ver Corte Constitucional de Colombia. Sentencia C-250 del 2012 (M.P. Humberto Antonio Sierra Porto: Marzo 28 del 2012). 
pensional y en general se les niegan sus derechos, pues se les exigen cargas no contempladas en la legislación, como es el caso de la apertura de la sucesión o la finalización formal del vínculo matrimonial o la declaración de la unión, entre otros requisitos que piden las entidades, en especial entidades del Estado. Así por ejemplo, esta Corporación plantea que si con el fin de obtener la sustitución pensional, los compañeros permanentes ya acreditaron su calidad, incluso mediante sentencia judicial, mal puede el Estado exigirle requisitos no contemplados en la Ley ni tampoco extender este perjuicio a otros beneficiarios de la sustitución pensional, para esto remite al art. 46 de la Ley 100 de 1993, modificado por el art. 12 de la Ley 797 del 2003. Del mismo modo, ante la negación de incluir al compañero(a) permanente como beneficiario de la seguridad social de su compañero a causa de la no formalización de la separación de este con su cónyuge, el Consejo de Estado estipula que debe otorgársele este derecho, pues, pese a que las disposiciones regulativas en este aspecto contemplan que para la respectiva afiliación a seguridad social debe hacerse afectiva la separación, el compañero permanente no es el responsable de que se realice este trámite, y si ya se encuentra acreditada la existencia de la unión marital de hecho y es probada su convivencia, no puede causársele un desmedro a su derecho fundamental a la seguridad social. Finalmente, de este problema jurídico puede afirmarse que para el periodo 2005-2011, respecto a seguridad social y sustitución pensional no hubo ningún pronunciamiento en que el Consejo de Estado hubiere dado un trato desigual a los compañeros permanentes, privilegiando al cónyuge únicamente, o favoreciendo a una u otra relación derivada del parentesco, todo con base en postulados de igualdad y prohibición constitucional de discriminación en razón del origen o forma de configuración familiar.

\section{REFERENCIAS}

CarlosFradiqueMéndez.Lafamiliafrentealaleyylavida.http:// www.acj.org.co/o/activ_acad.php?mod=posesion $\% 20$ fradique\%20mendez. Enero del 2012.

Código de Procedimiento Civil [CPC]. (Colombia). Decretos número 1400 y 2019 de 1970 . Agosto 6 y Octubre 26 de 1970.

Corte Constitucional de Colombia. Sentencia C-239 de 1994. (M.P. Jorge Arango Mejía: Mayo 19 de 1994).
Corte Constitucional de Colombia. Sentencia C-174 de 1996. (M.P. Jorge Arango Mejía: Abril 29 de 1996).

Corte Constitucional de Colombia. Sentencia C-075 del 2007. (M.P. Rodrigo Escobar Gil: Febrero 7 del 2007).

Corte Constitucional de Colombia. Sentencia C-283 del 2011. (M.P. Jorge Ignacio Pretelt Chaljub: Abril 13 del 2011).

Corte Constitucional de Colombia. Sentencia C-238 del 2012. (M.P. Gabriel Eduardo Mendoza Martelo: Marzo 22 del 2012).

Corte Constitucional de Colombia. Sentencia C-250 del 2012. (M.P. Humberto Antonio Sierra Porto: Marzo 28 del 2012).

Corte Suprema de Justicia de Colombia. Auto del 28 de noviembre del 2001. (Expediente: 1999-482).

Corte Suprema de Justicia de Colombia. Sala de Casación Civil. Proceso 2004-205. (M.P. Jaime Alberto Arrubla Paucar: Junio 18 del 2008).

Corte Suprema de Justicia de Colombia. Sala de Casación Civil. Proceso 2002-197. (M.P. William Namén Vargas: Marzo 11 del 2009).

Daniel Bonilla. Corte Constitucional, igualdad y orientación sexual. http://www.viva.org.co/cajavirtual/svc0051/articulo02.pdf. Enero del 2012.

Diego Eduardo López Medina. El derecho de los Jueces. 2ed. Legis. (2006).

John Rawls. La teoría de la justicia. Fondo de Cultura Económica. (2006).

Jürgen Habermas. Facticidad y validez. Trotta. (1998).

H. Mazeaud, \& J. Mazeaud. La familia. V. 4 P. II. Lecciones de derecho civil. Ediciones Juridicas Europea-A.M. (1959).

Jurispedia: El Derecho Compartido. http://es.jurispedia.org/ index.php/Lopez_Medina,_Diego_Eduardo. Enero 2012. 